
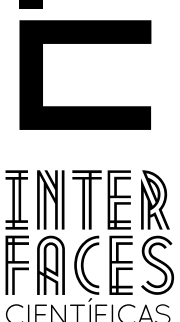

HUMANASE SOCIAIS

ISSN IMPRESSO 2316-333X

ISSN ELETRÔNICO 2316-3828

\title{
O DESCAMINHO DO ENSINO DA GRAMÁTICA
}

Carlos Alexandre N. Aragão ${ }^{1}$

\section{RESUMO}

0 presente texto faz uma abordagem acerca da institucionalização da gramática e da sua perpetuação há vários séculos no espaço escolar. Pelo que se tem examinado, percebe-se que o professor de Língua Portuguesa e a sociedade em geral ainda estão pautados em práticas tradicionais de ensino, mais precisamente, no ensino da Gramática Normativa, corroborando a perspectiva do "certo" versus o "errado". Tal abordagem, por seu turno, advém de uma visão de norma postulada desde os gregos que adentrou no universo escolar e social como um poder que jamais poderá ser questionado.

Com efeito, tem provocado um grande quantitativo de desistência por parte do estudante, no âmbito da Escola Pública, haja vista a repetição de exercícios estruturais, fazendo com que ele não perceba a língua como dinâmica, histórica e dialógica. Esse pensamento vai além dos muros escolares e é concebido pela mídia, como foi a discussão sobre o livro didático "Por uma vida melhor".

\section{PALAVRAS-CHAVE}

Gramática. Ensino. História. 


\section{ABSTRACT}

This paper presents an approach on the institutionalization of grammar and its perpetuation for centuries in the school. From what has been examined, one realizes that the teacher of Portuguese Language and the society in general are still guided by traditional teaching practices, more precisely, in the teaching of Normative Grammar, corroborating the view of the "right" versus "wrong". Such approach comes from a standard view postulated by the Greeks who entered in the scholar and social universe in such a powerful way that makes it unquestionable. Indeed, it has caused a large quantity of withdrawal of students from public schools, given the structural repetition of exercises, making it difficult for the students to perceive the language as a dynamic, historical and dialogical tool. This thinking goes beyond the school walls and is designed by the media, as it was discussed in the textbook "Por uma vida melhor."

\section{KEYWORDS}

Grammar. Education. History.

\section{RESUMEN}

Este artículo presenta una discusión sobre la institucionalización de la gramática y su permanencia durante siglos en la escuela. Por lo que se ha examinado, uno se da cuenta de que el profesor de Lengua Portuguesa y la sociedad en general están siempre guiados por las prácticas tradicionales de enseñanza y más precisamente en la enseñanza de la gramática normativa, lo que corrobora la perspectiva de lo "correcto" frente a lo "incorrecto". Este enfoque, a su vez, proviene de una visión de la norma postulada desde los griegos, que se fue incorporando en la escuela y en el universo escolar como un poder social que no puede ser cuestionado. De hecho, ha causado una gran cantidad de abandono por el estudiante dentro de la escuela pública, dada la repetición de ejercicios estructurals, por los que no se percibe la lengua como un dinámica, histórica y dialógica. Este pensamiento va más allá de los muros de la escuela y está diseñado por los medios de comunicación, como fue el debate sobre el libro de texto "Por uma vida melhor".

\section{PALABRAS CLAVE}

Gramática. Enseñanza. Historia.

\section{INTRODUÇ̄̃O}

O ensino de Língua Portuguesa vem sendo pesquisado por vários estudiosos da linguagem que defendem esse ensino livre das amarras da Gramática, como Possenti (1997), Geraldi $(1984,2004)$ e Barros (2008, 2010), mas, mesmo assim, o que se vê na sala de aula é o ensino de língua sendo tratado como ensino da gramática, preso à transmissão de regras apesar de os professores conhecerem as teorias da ciência Linguística durante a sua formação no curso de Letras, seja ele na modalidade presencial ou a distancia.

A perspectiva de ensino centrada na gramática deve-se a fatores sócio-históricos que permeiam esse universo desde a antiguidade clássica (Grécia e Roma), produzindo uma teia de exclusão e silenciamento dos educandos. Essa concepção de ensino está tão enraizada na sociedade que ultrapassa os muros escolares sendo partilhado, também, pela mídia. Recentemente assistimos à polêmica sobre adoção do livro didático "Por uma vida melhor" pelo Ministério da Educação (MEC) para as turmas da Educação de Jovens e Adultos (EJA), cuja autora, em uma das atividades, sugeria que os seus leitores, no caso, os alu- 
nos, fizessem uso da língua sem se aterem a norma padrão. Diante deste episódio, procuramos fazer uma historicização da institucionalização da gramática à luz de Kristeva (2007), relacionando a institucionalização da gramática à discussão gerada após a adoção do livro didático pelo MEC.

\section{A INSTITUCIONALIZAÇÃO DA GRAMÁTICA}

Sabemos que, após os fenícios fazerem uso da escrita alfabética, a outra civilização que se ateve a tal mecanismo foi a grega. Para isso fez adaptações do alfabeto fenício às características da língua grega como bem argumenta Kristeva (2007). Dessa forma, percebemos que o estudo da linguagem ganha uma atenção especial desde a escrita alfabética até a criação da gramática. Isso já era possível ser observado na obra "Crátilo", de Platão (429-347 a.C.), quando este filósofo discute a respeito da linguagem. Podemos também dizer que os gregos entendiam a linguagem como um sistema formal, distinto de um exterior significado por ela (o real), constituindo em si mesma um domínio próprio (KRISTEVA, 2007). Por ser um sistema formal, torna-se, na visão de Platão, uma obrigação, isto é, uma lei para toda a sociedade.

Nesse sentido, a linguagem passa a ser vista como um instrumento do conhecimento por representar uma função didática. Essa representação deve-se ao fato de constituir uma obrigação universal: todos os cidadãos deveriam adquiri-la e, ao mesmo tempo, saber usá-la.

No entanto, é na Alexandria que se assiste ao desenvolvimento de uma gramática especializada, diferente dos postulados teóricos dos estoicos, baseados na filosofia e na lógica. 0 modelo de gramática lançado pelos alexandrinos torna-se o exemplo da gramática ocidental tradicional. Nesse caminho, é Dionísio da Trácia (170-90 a. C. ) o responsável pelo modelo ainda hoje reconhecido nas obras gramaticais do ocidente. Ele via a gramática como uma arte, por defini-la como o saber empírico da linguagem dos poetas e dos pro- sadores. A gramática deste filósofo, por sua vez, estava voltada para a Morfologia. Os alexandrinos, por seu turno, são seguidores históricos dos estoicos e, de acordo com Mattos e Silva (2000, p. 17), “[... ] fixaram na tradição gramatical o 'erro clássico', como batizou Lyons (1979) [. . .]". Isso ocorre na medida em que aqueles filósofos tomam como base de uma escrita certa a dos escritores reconhecidos, instaurando a tão propalada discussão acerca do certo versus o errado. É nesse caminho que se reconhece a Grécia como o berço dos gramáticos do Ocidente, cuja função é ensinar o difícil idioma de Homero. Para o estudo da sintaxe, volta-se o olhar para o gramático Apolônio Díscolo (Séc. II, a. C. ), criador da primeira sintaxe, voltada mais para a filosofia do que a linguística.

Ao adquirir o saber grego sobre a língua, os gramáticos alexandrinos chegaram a Roma, transmitindo para este povo todo o conhecimento adquirido, desde a filosofia até a gramática. Com efeito, essa civilização obtém o modelo de gramática que tanto se tornou popular no ocidente. Entre os estudos dos gramáticos latinos o que ganhou mais destaque foi o de Varrão, com sua obra "De Língua Latina”. Nesta, ele propõe uma gramática do latim padrão. Nessa perspectiva, "a gramática consiste na arte de escrever e falar corretamente, de compreender os poetas" (MATTOS E SILVA, 2000, p. 19). O pensamento dos romanos, quanto à teoria da linguagem, assemelha-se ao dos gregos, pois a concebem como um jogo de normas. Por conseguinte, a gramática é o instrumento regulamentador de todas as regras seguidas pelos cidadãos falantes do Latim. Dessa forma, a gramática passa a ser definida como a base de qualquer ciência por expressar uma verdade 
que jamais pode ser questionada, ocupando um lugar de prestígio nas sociedades, conforme o pensamento de Varrão. Mas é com a publicação da obra “/nstitutiones Grammaticae”, de Prisciano, que a gramática latina atinge o seu apogeu. É nela que se encontra a primeira sintaxe da língua latina. Esta se torna modelo para todos os gramáticos da Idade Média.

No Renascimento, apesar do prestígio de outrora, - Latim ainda continua sendo o padrão para todos os outros idiomas estudados. Apesar da utilização dos cânones latinos, a sua teoria sofre modificações no ato de adaptação às línguas que não gozavam de tão prestigio. Esse fato leva ao desprestígio do Latim. Entretanto, é importante enfatizar que, nesta época, essa língua foi usada como objeto de ensino. Tal atitude corrobora o pensamento que os romanos tinham quanto à função da gramática de expressar uma verdade, a correta. Nesse sentido, a gramática passa a ser um instrumento regulador das normas aceitáveis pela sociedade culta, repassadas, através do ensino, para todos os falantes frequentadores, mesmo sendo em um número muito inferior, dos bancos escolares.

A partir daí, a gramática é concebida como uma disciplina, estudada e ministrada como a filosofia, no espaço escolar. Consequentemente, ganha um lugar de prestígio nessa instituição. Portanto, a gramática passa a ser uma disciplina autônoma e obrigatória. Não se despreza, porém, que tal prática é igualmente advinda dos gregos (KRISTEVA, 2007).

Apesar de alguns autores seguirem explicitamente o modelo antigo, outros preferiam seguir o modelo de gramática de Port-Royal, como foi o caso de Jerônimo Soares Barbosa. Esse estudioso colaborou tanto para o aprofundamento das teorias da LP quanto para a pedagogia do ensino do português. Assim, critica alguns gramáticos que o antecederam por seguirem, rigorosamente, o modelo latino e define a gramática como sendo a arte que ensina a pronunciar, escrever e falar corretamente qualquer língua. Tal postulado ilustra mais ainda o pensamento de Varrão mencio- nado anteriormente. Devemos lembrar que a gramática do Latim foi usada como exemplo para o ensino da gramática do Português, pois o ensino desta era comparado e contrastado com o daquela. Com o passar do tempo, a gramática da língua latina passa a ser ignorada pelos estudiosos, perdendo, assim, espaço, valor social, abrindo caminho para a consolidação da autonomia do Português. Segundo Mattos e Silva (2000, p. 47), “[. . . ] a atuação do ensino da gramática se exerceria em disciplinar, sobretudo o uso escrito e o uso oral formal, objetivo, aliás, final das gramáticas racionais".

Observamos que desde o Sec. XVI a gramática desfruta de alguns privilégios no que se refere ao ensino de língua, isso se deve ao fato de o seu surgimento ser a partir da Retórica e da Poética. Outro ponto é a valorização dada ao pensamento do falar e escrever corretamente. Alguns estudiosos não concordam com o ensino da gramática como é o caso de Ferreira França apud Oliveira (2010, p. 89). Para ele, não seria necessário dizer o que é nome, verbo e nem tão pouco quais as partes da oração são essenciais ou acessórias, mas sim mostrar através de exemplos que é a partir do uso que podemos descobrir tais conceitos/ normas. Esse lugar de privilégio dado à gramática representa um poder instituído pela classe dominante, isto é, pela classe que tem contato com a leitura e escrita. Dessa forma, cria meios de exclusão para aqueles que não fazem parte desse universo. 0 indivíduo que queira adentrar nesse ambiente deve saber falar e escrever corretamente; caso contrário, será retaliado. Tal pensamento está muito presente no espaço escolar quando observamos a relação de poder entre professor $x$ aluno, aluno (classe média alta) $x$ aluno (classe baixa).

Nos anos 1960, do séc. XX, chega aos cursos de Letras do Brasil a Linguística, trazendo as teorias estruturalistas (língua como um sistema de regras) que são perpassadas para as gramáticas pedagógicas. Reforça-se, assim, o pensamento tradicionalista existente quanto ao ensino de língua, conforme já mencionado. 
Nessa mesma época, o ensino de língua sofre influência das teorias de Comunicação; consequentemente, a disciplina de Português sofre alteração em sua nomenclatura, passando a se chamar Comunicação e Expressão. De acordo com Soares (1996), a concepção da língua como comunicação substitui as concepções de língua como um sistema. Há uma suposta nova direção de ensino, entretanto, da mesma forma que a anterior, traz em seu bojo a perspectiva de aquisição de um código. Aprender a ler, então, consiste em decodificar o código escrito. Consoante tal perspectiva de língua, há um continuísmo relacionado ao seu ensino. Apesar de existir um direcionamento linguístico, no que diz respeito ao ensino de língua, ainda é perpetuada a forma, segundo a qual os sujeitos aprendizes têm que adquirir a norma.

Segundo Cereja (2002), esse fato deve-se à forte força da tradição de ensino de língua fincado na cristalização do ensino de gramática, por ser consagrado, devido à ligação com a antiguidade greco-latina. Diante desse acontecimento, alguns linguistas questionam o rigor da gramática normativa, culminando com a formulação de propostas renovadoras para 0 ensino de língua, como é o caso de Possenti (2004), Geraldi (2004), Barros (2008), Bagno (2004). Tais propostas baseiam-se no ensino de língua voltado para o caráter da dinamicidade e não preso a estrutura como é o caso do ensino de texto centrado na busca da real significância do texto, são aceitas pelos professores de LP, mas eles não conseguem desenvolvê-las em sala de aula por não seguirem uma sequência didática, como bem faz o livro didático. Sabemos que não é esse o objetivo dos pesquisadores, mas mostrar aos docentes que a língua é dinâmica, pluriforme e multifacetada (LARA, 2003, p. 85).

Mesmo com a presença da Linguística, há quase 50 anos, nos cursos de Letras e de várias pesquisas no campo da linguagem, muitos professores de LP de hoje insistem em permanecer no ensino canônico de língua, privilegiando o uso da metalinguagem e da obediência às regras da gramática normativa. Nem a publicação dos PCNs, em 1998, consegue mudar tal realidade. De acordo com Lara (2003), apesar de esse instrumento enfatizar o uso do texto como ponto de partida para as atividades de leitura, escrita e prática de análise linguística, dando ao aluno a possibilidade de explorar a língua em diferentes contextos de usos, o que se observa no dia-a-dia da sala de aula é um cenário muito diferente que privilegia o modelo clássico de ensinar a língua portuguesa, centrado na gramática normativa. Essa escolha causa efeitos devastadores como a exclusão de muitos estudantes que não sabem usar as normas gramaticais como a escola determina.

Diante disso, é necessário que a escola modifique a ideia de ensino de língua para que todos os seus partícipes possam ser respeitados e consigam compreender a língua como um processo dinâmico. Caso isso não aconteça, a língua continua como representação do mundo e do pensamento e ganha proporções além do espaço escolar, como veremos no próximo tópico a repercussão da polêmica sobre a adoção do livro didático “Por uma vida melhor" pelo MEC.

\section{A GRAMÁTICA X LIVRO DIDÁTICO}

Recentemente, presenciamos a grande discussão gerada pela aprovação do livro "Por uma vida melhor" pelo Ministério da Educação (MEC) para os estudan- tes da Educação de Jovens e Adultos (EJA) onde a escritora coloca: 


\section{Os livros ilustrados mais interessantes estão emprestados.}

Você pode estar se perguntando: "Mas eu posso falar 'os livro?"'

Claro que pode. Mas fique atento porque, dependendo da situação, você corre o risco de ser vítima de preconceito linguístico. Muita gente diz o que se deve e o que não se deve falar e escrever, tomando as regras estabelecidas para a norma culta como padrão de correção de todas as formas linguísticas. O falante, portanto, tem de ser capaz de usar a variante adequada da língua para cada ocasião.

Existe outro tipo de concordância: a que envolve o verbo. Observe seu funcionamento:
0 menino pegou o peixe. menino $\rightarrow$ singular pegou $\rightarrow$ singular
Diante da repercussão gerada com a aprovação deste manual didático, observamos que a forte tradição do ensino de língua, ou melhor, do ensino de gramática nas aulas de língua, continua presente na escola e na sociedade, onde exclui alguns falares e privilegiam outros. Isso se deve ao fato desse ensino continuar preso ao conceito postulado por Varrão, mesmo com a presença da Linguística nos cursos de Letras. Isso evidencia o poder dado à norma padrão e em especial a escrita. Consequentemente, se cria um processo de desvalorização das normas socioeconomicamente desprestigiadas.

Não podemos esquecer que o livro foi feito para pessoas que adentram no sistema escolar com uma idade avançada e que já trazem consigo uma gama de conhecimentos a serem trabalhados pelo docente. Portanto, a orientação dada aos professores que trabalham com tal modalidade é que iniciem o ensino a partir do conhecimento de vida desses discentes, como bem fez o educador Paulo Freire. Segundo Bezerra (2011) é preciso que a escola comece a fazer uso dos mecanismos reais, isto é, da vivência do aprendiz para se chegar ao ideal que a escola quer inculcar nos seus aprendizes.

Devido a tal orientação, a escritora do livro aprovado pelo MEC tenta criar um diálogo entre autor e leitor de forma interativa, utilizando-se de uma linguagem presente no cotidiano desses aprendizes. Isso é possível de perceber quando ela pergunta "Mas eu posso falar os livro? Claro que pode". Essa abordagem está relacionada à concepção de linguagem enquanto forma de interação entre os sujeitos. Nesse sentido, o aprendiz é visto como um sujeito ativo que é capaz de construir o seu próprio conhecimento, por isso ela afirma "O falante, portanto, tem de ser capaz de usar a variante adequada da língua para cada ocasião". Devemos lembrar que as pessoas já falam dessa maneira.

Mas podemos observar que o ensino de língua, por se concentrar no ensino de gramática, ainda está pautado no pensamento da concepção de linguagem enquanto representação do pensamento e do mundo, cuja ação do indivíduo é seguir as regras impostas sem questioná-las, sem ser percebido como um sujeito ativo e sim passivo diante da língua.

Segundo Possenti (2011), nenhum linguista propõe que deve ensinar os educandos a falarem "Os livro" e nem tão pouco foi a intenção da autora do livro, porque as pessoas já sabem falar. Muitos críticos não leram o livro por completo para tecer comentários, mas sim apenas o fragmento que colocamos acima. Lembramos também que, em nenhum momento, foi desprezado o modelo padrão que tanto o espaço escolar privilegia, pois este permaneceu sendo o objetivo da fala da autora que parte do falar popular para chegar a um padrão como bem salientou Bezerra (2011). Sendo assim, devemos repensar como o ensino de língua vem sendo realizado nas nossas salas de aula para que novos episódios não venham a ocorrer.

Observamos que a polêmica criada por alguns estudiosos da linguagem e pela mídia deu-se porque esse manual didático vai de encontro ao que a gramática normativa postula, já que, há vários séculos, vem sendo utilizada como a única forma "correta" de se escrever e falar. É um poder que adentra na escola, na família e na sociedade como sendo o único meio usado pelo indivíduo para ser aceito socialmente. 


\section{CONSIDERACOÕES FINAIS}

É preciso que professores, estudantes, estudiosos da língua e a mídia concebam a língua como um espaço dinâmico, flexível e multifacetado, capaz de se modificar a partir da interação dos sujeitos e não como algo estático e fechado em regras/normas que devem ser usadas em espaços isolados, pois através da lin-

\section{REFERÊNCIAS}

AGUIAR, C. A. de. Por uma vida melhor. Coleção Viver, Aprender. Educação de Jovens e Adultos. Volume 2. São Paulo, 2011.

BAGNO, M. Preconceito linguístico: o que é, como se faz. 34. Ed. São Paulo: Loyola, 2004.

BAKHTIN, M. Marxismo e filosofia da linguagem: problemas fundamentais do método sociológico da linguagem. 13. ed. São Paulo: Hucitec, 2009.

BARROS. M. E. de R. de A. B. "A língua portuguesa na escola: percurso e perspectiva”, Revista Interdisciplinar. v. 6. 2008.

BARROS. M. E. de R. de A. B. Fundamentos para o ensino da alfabetização. São Cristóvão: Universidade Federal de Sergipe / CESAD, 2010.

BEZERRA, A. P. Entrevista ao SETV $2^{\mathrm{a}}$ edição.

CASTILHO, A. T. A Língua falada no ensino de português. São Paulo: Contexto, 1998.

CEREJA, W. R. Ensino de Língua Portuguesa: entre a tradição e a enunciação. In: HENRIQUES, C. C. ; PEREIRA, M. T. G. (Orgs. ). Língua e transdisciplinaridade: rumos, conexões, sentidos. São Paulo: Contexto, 2002, p. 153-160. guagem o indivíduo transforma o seu meio e consegue se constituir enquanto tal. Esse pensamento deve adentrar no espaço escolar e na mídia para que não vejamos mais episódio dessa natureza, onde presenciamos mais uma vez a força do poder institucionalizado diante do desprivilegiado.

COSTA, G. R. da. 0 Gestar II - A formação de professores de português: numa perspectiva discursiva. São Cristovão - SE, 2011. Dissertação (Mestrado) UFS.

FARACO, C. A. Linguagem e diálogo: as ideias linguísticas do círculo de Bakhtin. Curitiba: Edições Criar, 2003.

GERALDI, J. W. Concepções de linguagem e ensino de português. In: GERALDI, João Wanderley (org. ). 0 texto na sala de aula: leitura e produção. Cascavel: ASSOESTE, 1984.

GERALDI, J. W. Unidades básicas do ensino de Português. In: GERALDI, J. W. (org. ). 0 texto na sala de aula: leitura e produção. São Paulo: Ed. Ática, 2004.

GUIMARÃES, E. A Língua Portuguesa no Brasil. In: Línguas do Brasil. Ciência e Cultura. Revista da SBPC. Ano 57. N 2. Abril - junho, 2005, p. 24-28.

JAKOBSON, R. Linguística e comunicação. 8. ed. São Paulo: CULTRIX, 1975.

KOCH, I. G. V. A inter-ação pela linguagem. 2. ed. São Paulo: Contexto, 1995.

KRISTEVA, J. História da Linguagem. Trad. Margarida Barahona. Lisboa: Edições 70, 2007. 
LARA, G. M. P. O discurso do professor de português e suas implicações para o ensino da disciplina. In: Estudos de linguagem: inter-relações e perspectivas. Campo Grande, MS: Ed. UFMS, 2003.

LUFT, C. P. Língua e liberdade. 3. Ed. São Paulo: Ática, 1994.

LYONS, J. Introdução à Linguística Teórica. São Paulo: C. E. N. ,1979.

MARCUSCHI, L. A. 0 papel da linguística no ensino de línguas. Conferência pronunciada no $1^{\circ}$ Encontro de Estudos Linguístico-culturais na UFPE, Centro de Artes e Comunicação, Recife, PE, 2000.

MENDONÇA, M. C. Língua e Ensino: políticas de fechamento. In MUSSALIM, Fernanda (Orgs. ). Introdução à linguística: domínios e fronteiras. 6. ed. São Paulo: Cortez, 2009.

OLIVEIRA, L. E. Gramaticalização e Escolarização: contribuições para uma história do ensino das línguas no Brasil (1757-1827). São Cristovão/Aracaju: Editora UFS/Fundação Oviêdo Teixeira, 2010.
ORLANDI, E. P. Introdução às ciências da linguagem: discurso e textualidade. 2. e

d. Campinas: Pontes, 2010.

Parâmetros Curriculares Nacionais: língua portuguesa / Ministério da Educação. Secretaria da Educação Fundamental. - 3. ed. - Brasília: A Secretaria, 2001.

POSSENTI, S. Aceitam tudo. Terra Magazine: colunistas, 2011.

POSSENTI, S. Sobre o ensino de Português na escola. In: GERALDI, J. W. (org. ). 0 texto na sala de aula: leitura e produção. São Paulo: Ed. Ática, 2004, p. 32-38.

MATTOS E SILVA, R. V. . Tradição gramatical e gramática tradicional. 4 ed. São Paulo: Contexto, 2000.

SOARES, M. Português na escola: história de uma disciplina curricular. Material de divulgação da obra Português através de textos. São Paulo: Moderna, 1996. 